\title{
Evolution of protein bound Maillard reaction end-products and free Amadori compounds in low lactose milk in presence of fructosamine oxidase I
}

\author{
Antonio Dario Troise, ${ }^{\mathrm{a}, *}$ Martina Buonanno, ${ }^{\mathrm{b}, \mathrm{c}}$ Alberto Fiore, ${ }^{\mathrm{d}}$ Simona Maria Monti, ${ }^{\mathrm{b}, *}$ Vincenzo Fogliano ${ }^{\mathrm{e}}$ \\ a Department of Agriculture and Food Science, University of Naples Federico II, Italy \\ b Institute of Biostructures and Bioimaging (IBB), CNR, via Mezzocannone 16, 80134 Naples, Italy \\ ${ }^{c}$ Dipartimento di Scienze e Tecnologie Ambientali, Biologiche e Farmaceutiche, Seconda Università di Napoli, I-81100 Caserta, Italy \\ ${ }^{\mathrm{d}}$ School of Science, Engineering \& Technology, Division of Food Science, Abertay University, Dundee DD1 1HG, UK \\ ${ }^{\mathrm{e}}$ Food Quality Design Group, Wageningen University, PO Box 8129, 6700 EV Wageningen, The Netherlands
}

A R T I C L E I N F O

Article history:

Received 24 February 2016

Received in revised form 13 June 2016

Accepted 14 June 2016

Available online xxx

Chemical compounds studied in this article:

Ne-(2-Furoylmethyl)-L-lysine (furosine, PubChem CID:123889)

$N \varepsilon$-(Carboxymethyl)-L-lysine (CML, PubChem CID:123800)

lysine (PubChem CID:5962)

D-Glucose (PubChem CID:5793)

$\mathrm{N}$-(1-Deoxy-D-fructos-1-yl)-L-leucine

(PubChem CID:71316981)

N-(1-Deoxy-D-fructos-1-yl)-L-pheny-

lalanine (PubChem CID:71316982)

$N$-(1-Deoxy-D-fructos-1-yl)-L-Lysine (PubChem CID:123708)

N-(1-Deoxy-D-fructos-1-yl)-L-Glycine (PubChem CID:3081391)

N-(1-Deoxy-D-fructos-1-yl)-L-Valine

(PubChem CID:71777427)

$\mathrm{N}$-(1-Deoxy-D-fructos-1-yl)-L-Tryptophan (PubChem CID:159983)

$N$-(1-Deoxy-D-fructos-1-yl)-L-Tyrosine

(PubChem CID:no items)

$N$-(1-Deoxy-D-fructos-1-yl)-L-Serine (PubChem CID:no items)

N-(1-Deoxy-D-fructos-1-yl)-L-Cysteine

(PubChem CID:no items)

$N$-(1-Deoxy-D-fructos-1-yl)-L-Threo-

nine (PubChem CID:no items)

$N$-(1-Deoxy-D-fructos-1-yl)-L-Gluta-

mine (PubChem CID:no items)

$N$-(1-Deoxy-D-fructos-1-yl)-L-As-

paragine (PubChem CID:71316980)

\section{Introduction}

Abbreviations: APs, Amadori products; MR, Maillard reaction; MRPs, Maillard reaction end products; HRMS, high resolution mass spectrometry; CML, NE-(Carboxymethyl)-L-lysine; furosine, $N \varepsilon$-(2-Furoylmethyl)-L-lysine; Faox, fruc-

tosamine oxidases

* Corresponding authors.

Email addresses: antoniodario.troise2@unina.it (A.D. Troise); marmonti@unina.it (S.M. Monti) 
$\mathrm{N}$-(1-Deoxy-D-fructos-1-yl)-L-Glutamic acid (PubChem CID:56971968) $N$-(1-Deoxy-D-fructos-1-yl)-L-Arginine acid (PubChem CID:no items)

$N$-(1-Deoxy-D-fructos-1-yl)-L-Histidine acid (PubChem CID:no items) $N$-(1-Deoxy-D-fructos-1-yl)-L-Proline acid (PubChem CID:71316983)

Keywords:

Fructosamine oxidase I

Maillard reaction

MRPs

Amadori products

Low lactose milk

Mass spectrometry

Amadoriase

\section{A B S T R A C T}

Thermal treatments and storage influence milk quality, particularly in low lactose milk as the higher concentration of reducing sugars can lead to the increased formation of the Maillard reaction products (MRPs). The control of the Amadori products (APs) formation is the key step to mitigate the Maillard reaction (MR) in milk. The use of fructosamine oxidases, (Faox) provided promising results. In this paper, the effects of Faox I were evaluated by monitoring the concentration of free and bound MRPs in low lactose milk during shelf life. Results showed that the enzyme reduced the formation of protein-bound MRPs down to $79 \%$ after six days at $37{ }^{\circ} \mathrm{C}$. Faox I lowered the glycation of almost all the free amino acids resulting effective on basic and polar amino acids. Data here reported corroborate previous findings on the potentiality of Faox enzymes in controlling the early stage of the MR in foods.

C) 2016 Published by Elsevier Ltd. tion of amino group with disaccharide lactose or other reducing sugars are involved in further degradation promoting the formation of crosslink products, $\alpha$-dicarbonyls, hydroxycarbonyls, deoxyosones, such as 1-deoxyosone or 3-deoxyosone, 1-amino-1,4-dideoxyosones and Strecker degradation (Henle, 2005; Nursten, 2005). Also free amino acids react in milk with reducing carbonyls, contributing to formation of N-(1-deoxy-D-fructos-1-yl)-L-amino acids, or fructose-amino acids which cause an overall reduction of milk nutritive value (Mossine \& Mawhinney, 2010; Pischetsrieder \& Henle, 2012) and lead to the formation of volatile off-flavor and undesired molecules (van Boekel, 1998).

According to the increase of thermal loading or to the prolonged storage, Maillard reaction end products (MRPs) are formed. Even though MRPs consumption has been related to several beneficial properties such as antioxidant activity (Bedinghaus \& Ockerman, 1995), chemopreventive activity (Somoza, 2005), antimutagenic actions (Friedman, 1996), it has been also reported that their formation leads to nutritional drawbacks (Hellwig \& Henle, 2014). Indeed, MRPs intake has been also considered a risk factor for many disease and the reduction of their formation before consumption could be of relevant importance for human health (Delgado-Andrade, Seiquer, Navarro, \& Morales, 2007).

Different strategies to mitigate the formation of the MRPs beginning from the very initial steps of the MR have been proposed (Troise $\&$ Fogliano, 2013) and among them the use of encapsulation and enzyme technologies have been deeply investigated by our group (Fiore et al., 2012; Troise, Fiore, et al., 2014).

Two FAD-fructosamine oxidase enzymes, namely Faox I and II, isolated from Aspergillus sp were investigated due to their ability of catalyzing the oxidative deglycation of low molecular weight APs to yield deoxyglucosone and amino acids (Takahashi, Pischetsrieder, \& Monnier, 1997a, 1997b). After the catalytic cycle, reduced FAD is oxidized by molecular oxygen with the concomitant release of one molecule of hydrogen peroxide (Wu, Takahashi, Chen, \& Monnier, 2000). These enzymes have a potential use in food industry in controlling MRPs formation (Troise, Dathan, et al., 2014). It has been demonstrated that they are able to promote deglycation of peptides and/or small proteins when enzymes were added before glycation up to $80 \%$, whereas no substantial effects were observed when incubated in a BSA-glucose system, likely due to the steric hindrance of the protein (Capuano et al., 2007; Mennella, Borrelli, Vinale, Ruocco, \& Fogliano, 2005). Preliminary data obtained in a commercial UHT low lactose milk incubated with and without Faox I and II at $37^{\circ} \mathrm{C}$ up to 17 days showed that protein-bound hydroxymethylfurfural (bHMF) was reduced of about $90 \%$ and $N \varepsilon$-(carboxymethyl)-L-lysine (CML) of about $60 \%$ highlighting the strong potentiality of enzymatic treatment as a tool for limiting MRPs formation (Troise, Fiore, et al., 2014).
In this study the deglycating capacity of Faox I has been evaluated by monitoring the formation of free Amadori compounds and the end markers of MR, such as CML and bound fructose-lysine $N \varepsilon$-(2-furoylmethyl)-L-lysine (furosine) in low lactose milk. This commercial product is becoming very popular due to the increase of self-perceived lactose intolerance and to the pleasant sweet taste; however the presence of glucose and galactose, which are much more reactive than lactose, can accelerate the formation of MRPs in respect to the conventional milk thus altering the sensory and nutritional profile of the products. In low lactose milk, the presence of monosaccharides promotes a more pronounced reactivity towards amino groups of protein and free amino acids. This scenario represents the background for the formation of several MRPs (Jansson et al., 2014). Results show the ability of Faox I in reducing low lactose milk glycation both looking at the APs and at the molecules formed at the advanced stage of the MR.

\section{Material and methods}

\subsection{Chemicals and reagents}

Acetonitrile, methanol and water for high resolution mass spectrometry, solid phase extraction and tandem mass spectrometry were obtained from Merck (Darmstadt, Germany). The ion pairing agents, perfluoropentanoic acid for chromatographic separation and $d 4$-lysine were all obtained from Sigma-Aldrich (St. Louis, MO). $N$-(1-Deoxy-D-fructos-1-yl)-L-phenylalanine and N-(1-deoxy-D-fructos-1-yl)-L-leucine, $d 4$-CML and CML were obtained from Toronto Research Chemicals (Toronto, Canada), while $N$-(1-deoxy-D-fructos-1-yl)-L-asparagine, $\quad N$-(1-deoxy-D-fructos-1-yl)-L-histidine, $N$-(1-deoxy-D-fructos-1-yl)-L-lysine and $N$-(1-deoxy-D-fructos-1-yl)-L-aspartic acid were synthetized according to established protocols (Troise, Fiore, Roviello, et al., 2015). The calibration solution for mass spectrometry recalibration (see "Amadori compounds analysis" section) was obtained from Thermo Fisher (Bremen, Germany).

\subsection{Expression and purification of Faox I}

Expression and purification of Faox I was performed according to Troise, Fiore, co-workers (2014). Briefly, after expression in BL21(DE3) cells (Novagen) $16 \mathrm{~h}$ at $20{ }^{\circ} \mathrm{C}$ in the presence of $0.1 \mathrm{mM}$ IPTG, Faox I was purified on a $1 \mathrm{ml}$ HisTrap HP column (GE Healthcare Little Chalfont, UK) eluting in $110 \mathrm{mM}$ imidazole , $20 \mathrm{mM}$ Tris, $250 \mathrm{mM} \mathrm{NaCl}, \mathrm{pH}$ 8.0. SenP2 protease cleaved protein was then concentrated and loaded on a Superdex 75 size exclusion column (GE Healthcare, Little Chalfont, UK), yielding a highly purified protein as monitored by SDS-Page and LC-ESI-MS. In order to check if purified Faox I enzyme was protease-free, $\beta$-lactoglobulin (10 
$\mathrm{mg} / \mathrm{mL}$ each, $0.2 \mathrm{M}$ phosphate buffer, $\mathrm{pH} 8.0$ ) was incubated at $37^{\circ} \mathrm{C}$ with Faox 1:100, 1:500, 1:1000 w:w, with trypsin 1:100, 1:500, $1: 1000 \mathrm{w}: \mathrm{w}$, and without any enzyme. In this latter case an equivalent volume of buffer was added in control samples not containing the enzyme. After 1 h, 3 h, 6 h, 1 day, 4 days, 7 days, samples were taken, immediately frozen and stored at $-20{ }^{\circ} \mathrm{C}$ until the analysis. Samples were analyzed by SDS-PAGE and obtained data compared. No proteolytic activity was monitored in samples incubated with Faox I enzyme, even at the high ratio of 1:100.

\subsection{Low lactose model system incubation}

Low lactose milk (lactose $<0.1 \%$ according to manufacturer nutrition facts) was purchased in a local market. Faox I enzyme was added at a protein ratio of 1:1000, whereas an equivalent volume of buffer was added in control samples not containing the enzyme. Samples were then mixed, aliquoted and stored at $37^{\circ} \mathrm{C}$ up to 12 days. After $0,6,9,12$ days samples were taken, immediately frozen and stored at $-20{ }^{\circ} \mathrm{C}$ until the analysis.

\subsection{Protein bound Maillard reaction products determination}

Protein bound MRPs and total lysine were quantified according to the procedure previously described (Troise, Fiore, Wiltafsky, et al., 2015). Briefly, $4 \mathrm{~mL}$ of hydrochloric acid (6 M ) were added to $0.1 \mathrm{~mL}$ of each sample in a screw capped flask with PTFE septa. The mixture was saturated by nitrogen (15 min at 2 bar) and hydrolyzed in an air forced circulating oven (Memmert, Schwabach, Germany) for $20 \mathrm{~h}$ at $110^{\circ} \mathrm{C}$. The mixture was filtrated by polyvinylidene fluoride filters (PVDF, 0.22 Millipore, Billerica, MA) and $400 \mu \mathrm{L}$ was dried under nitrogen flow. Samples were reconstituted in $380 \mu \mathrm{L}$ of water and $10 \mu \mathrm{L}$ of each internal standard $d 4$-Lys (for lysine and furosine quantification) and $d 4$-CML (for CML quantification) was added $(10 \mu \mathrm{g} / \mathrm{mL}$ for each). Samples were loaded onto equilibrated Oasis HLB $30 \mathrm{mg}$ cartridges (Waters, Wexford, Ireland) and eluted according to the method previously described, then $5 \mu \mathrm{L}$ was injected onto the LC-MS/MS system. Separation of furosine, CML, lysine and their respective internal standards was achieved on a reversed - phase core shell column (Kinetex C18 $2.6 \mu \mathrm{m}, 2.1 \mathrm{~mm} \times 100 \mathrm{~mm}$, Phenomenex, Torrance, CA) using the following mobile phases: A, $5 \mathrm{mM}$ perfluoropentanoic acid and $\mathrm{B}$, acetonitrile $5 \mathrm{mM}$ perfluoropentanoic acid. The compounds were eluted at $200 \mu \mathrm{L} / \mathrm{min}$ through the following gradient of solvent $\mathrm{B}(\mathrm{t}$ in $[\mathrm{min}] /[\% \mathrm{~B}]):(0 / 10),(2 / 10),(5 / 70),(7 / 70),(9 /$ $90),(10 / 90)$. Positive electrospray ionization in MRM mode was used for the detection by using an API 3000 triple quadrupole (ABSciex, Carlsbad, CA). The characteristic transitions, the source parameters and the nebulizing condition were optimized according to our previous paper (Troise, Fiore, Wiltafsky et al., 2015).

\subsection{Amadori compounds quantification}

Free Amadori compounds were quantified according to Troise, Fiore, Roviello, et al. (2015), Troise, Fiore, Wiltafsky, et al. (2015) with minor modification. For the chromatographic separation of APs from their respective amino acids, the mobile phases consisted of $5 \mathrm{mM}$ perfluoropentanoic acid (NFPA) in water (solvent A) and $5 \mathrm{mM}$ NFPA in acetonitrile (solvent B) by using the same gradient as previously described. The flow rate was set to $200 \mu \mathrm{L} / \mathrm{min}$ and the injection volume was $5 \mu \mathrm{L}$. The separation of APs was achieved through a thermostated $\left(30^{\circ} \mathrm{C}\right)$ Kinetex $2.6 \mu \mathrm{m}(100 \times 2.1 \mathrm{~mm})$ core-shell C-18 column (Phenomenex, Torrance, CA). The Accela 1250
UPLC system (Thermo Fisher Scientific, Bremen, Germany) was directly interfaced to an Exactive Orbitrap high-resolution mass spectrometer (Thermo Fisher Scientific, Bremen, Germany) and analytes were detected through a heated electrospray interface (HESI) operating in the positive mode and scanning the ions in the $\mathrm{m} / \mathrm{z}$ range $60-400$. The resolving power was set to 50,000 full width at half maximum (FWHM, $m / z 200$ ) resulting in a scan time of $1 \mathrm{~s}$. All the parameters were optimized according to the procedure previously described. Before interday analysis the instrument was externally calibrated by infusion of a solution that consisted of caffeine, Met-Arg-Phe-Ala (MRFA), fluorinated phosphazines Ultramark 1621, and acetic acid in a mixture of acetonitrile/methanol/water $(2: 1: 1, \mathrm{v} / \mathrm{v} / \mathrm{v})$ (Thermo Fisher, Bremen, Germany). The mass range tolerance was set to $5 \mathrm{ppm}$ and the exact mass of diisooctyl phthalate $\left([\mathrm{M}+\mathrm{H}]^{+}: 391.28429\right)$ was used as lock mass for the recalibration of the instrument during the analysis. The analytical performances were similar to the ones previously reported (Troise, Fiore, Roviello, et al., 2015).

\subsection{Statistical analysis}

Each sample was analyzed tree times from independent incubation sets and the results were reported as $\mathrm{mg} / 100 \mathrm{~g}$ of protein for lysine, furosine and CML, while free APs were reported as $\mathrm{mg} / \mathrm{L}$ of milk. The reduction of bound MRPs was calculated by dividing the difference between the concentration within the different incubation times in presence and in absence of Faox after subtracting the initial concentration. The influence of Faox on free APs was calculated by monitoring the ratio between the concentration in presence and in absence of Faox within the specific incubation time. Evolution of the bound and free markers was recorded by using Matlab R2009b (Mathworks, Natick, MA), while the principal component analysis, the FancyTiles schema and the Tukey test $(\alpha=0.05)$ for bound MRPs and for the sum of APs were performed by using XLStat (Addinsoft, New York, NY).

\section{Results}

Preliminary analysis were performed to verify that the purified enzyme was protease-free. No proteolytic activity was monitored in samples incubated with Faox I enzyme, even at the high ratio of 1:100 (data not shown).

\subsection{Faox activity on bound MRPs}

The concentration of total lysine, furosine and CML in LLM in presence and absence of FaoxI was monitored by ion pairing liquid chromatography tandem mass spectrometry and the results are presented in Fig. 1.

The influence of Faox on the bound fructose-lysine was evaluated via acidic hydrolysis and furosine detection. The concentration of furosine in the control samples ranged from $208.9 \pm 8.9-893.5 \pm 33.3 \mathrm{mg} / 100 \mathrm{~g}$ of protein after 9 days. A drop to $585.3 \pm 25.1 \mathrm{mg} / 100 \mathrm{~g}$ of protein was observed at 12 days, which is consistent with conversion of APs into advanced MRPs. In presence of the enzyme, furosine formation was delayed reaching a maximum value of $578.4 \pm 46.9$ only after 9 days. A maximum reduction of $79.4 \%$ of furosine was reached after 6 days incubation. The reduction of furosine was significant at all times $(\alpha<0.05)$.

At the beginning of the incubation, the amount of CML in LLM was of $2.6 \pm 0.2 \mathrm{mg} / 100 \mathrm{~g}$ protein. In LLM without Faox, CML increased during incubation time reaching its maximum after 9 days incubation with a concentration of $4.8 \pm 0.1 \mathrm{mg} / 100 \mathrm{~g}$ protein. After 

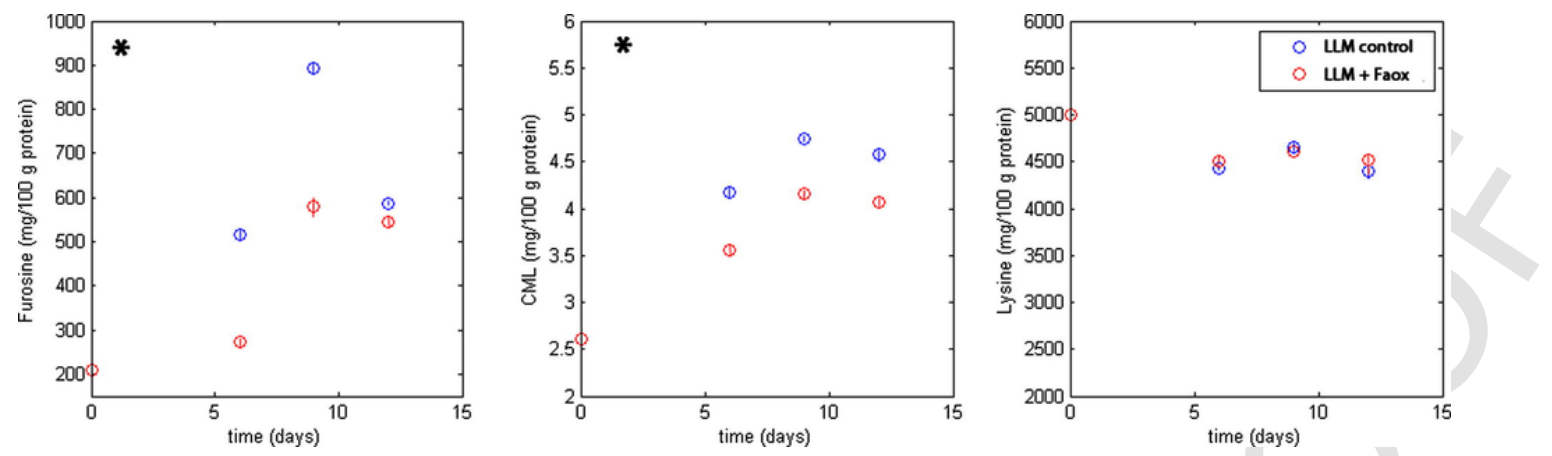

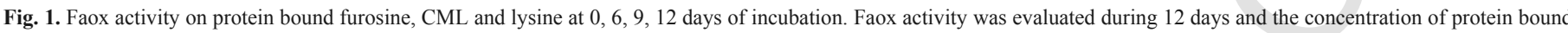

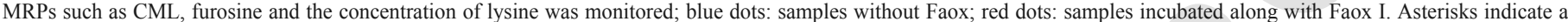

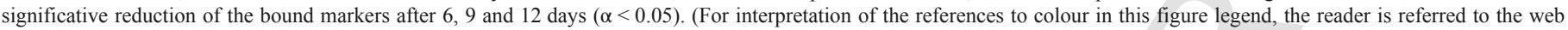
version of this article.)

this time the amount remained almost constant with a slight decrease after 12 days: $4.6 \pm 0.1 \mathrm{mg} / 100 \mathrm{~g}$ of protein. Samples added with Faox I showed a significative decrease in CML content during the whole time course compared to untreated samples $(\alpha<0.05)$. In presence of Faox, CML was reduced by $38.7 \%, 27.7 \%$ and $25.4 \%$ after 6 , 9 and 12 days respectively.

The effects of Faox I were evaluated also towards the concentration of total lysine. In both systems, with and without Faox, the concentration during the incubation ranged from $5000 \pm 15.6 \mathrm{mg} / 100 \mathrm{~g}$ to $4396.9 \pm 145.1 \mathrm{mg} / 100 \mathrm{~g}$ at the beginning and after 12 days, respectively. Interestingly, the concentration of total lysine was always higher in presence of the enzyme.

\subsection{Free Amadori compounds}

In Fig. 2, the loadings plot, the variables and the observations of the evolution of APs during twelve days incubation in presence and absence of Faox I are shown in order to provide a preliminary exploratory analysis of the effects of the Faox during the storage (Pripp, 2013). The first two principal components (axis PC1 and PC2) explained approximately $77 \%$ of the total data variance, including variance unique to each variable, variance common among variables, and error variance. Fig. $2 \mathrm{~A}$ revealed the relationship between the samples and the variables considered (i.e. the Amadori compounds). The Fig. 2B is the PCA score plot where no outliers were observed. This analysis revealed a defined clustering behavior, except for the two samples at the initial step of the incubation that, as expected, were close each other. The use of red (absence of Faox) and green (presence of Faox) circle helped in the visualization of the two clusters. In particular, PC1 and PC2 showed a clear distinction due to the effects of the enzyme: in presence of Faox I the loading plot showed both negative $\mathrm{PC} 1$ and PC2; in fact the three points were located in the third quarter. In absence of the enzyme the PC1 and PC2 were both positive. The only one exception was after twelve days of incubation where the PC1 was positive and PC2 negative making the observation located in the second quarter. The opposite location of the samples demonstrated a clear effectiveness of the enzyme in the reduction of free APs.

Results obtained measuring the free Amadori compounds showed in most of the cases (13 APs over 17 APs analyzed) decreased values in Faox I treated compared to control UHT LLM samples as highlighted in Fig. 3. Three boxes with three different color were used in order to visualize the effects of the enzyme on the overall reduction of free APs during the incubation. Green boxes highlighted a mean reduction across 12 days of free APs higher than 10\%; yellow boxes were used in three cases: $i$ ) a reduction lower than $10 \%, i i)$ similar values among samples with and without the enzyme, iii) an increase lower than $10 \%$; then with Fru-Pro a red box was used indicating an increase of the compound in presence of Faox I.

Among the APs, the catalytic effects of the enzyme were evident on basic APs, such as Fru-Arg and Fru-Lys whose amount significantly lowered compared to untreated samples during the incubation. In particular, already after six days of incubation, they were reduced by $50 \%$ and $53 \%$, respectively and this reduction was kept almost unchanged during time, in particular fructose-lysine was reduced up to $60 \%$ and fructose-arginine up to $58 \%$ after 9 days. In this respect FruHis represented an exception with only $3 \%$ and $5 \%$ reduction after 9 and 12 days. Aliphatic APs were also influenced by the addition of Faox I being reduced from 5\% for Fru-Ala after 6 days up to 52\% after 9 days for Fru-Val. The average reduction for aliphatic APs was 21\% during twelve days. Among the aromatic APs, Fru-Trp was reduced by the Faox action with a final reduction of $50 \%$ after 12 days incubation, while Fru-Phe and Fru-Tyr were almost constant. In particular in presence of Faox, Fru-Tyr at the end of incubation was below the limit of detection (LOD). On the contrary, the results for neutral APs were controversial in some cases. The reduction in presence of the enzyme ranged from $6 \%$ for Fru-Ser after 12 days up to 34\% and 36\% for FruGln and Fru-Cys after 6 days. Fru-Glu was the only one acidic AP detected and it was slightly reduced by the presence of Faox I, its reduction ranging from $6 \%$ to $10 \%$. The unique AP Fru-Gly was greatly influenced by Faox I during incubation, likely due to its low steric hindrance, being reduced from $6 \%$ after 6 days to $51 \%$ after 12 days of incubation. Finally, among the 18APs detected, only Fru-Pro showed a peculiar behavior since it was the only Amadori compound which continuously increased in presence of Faox I. It is worth noticing that its formation increased during incubation time up to $30 \%$ compared to untreated samples, while only a minor reduction of $6 \%$ was present at the beginning of the incubation.

As highlighted by the green boxes, overall significative reduction for the sum of APs in presence of the enzyme was $12 \%, 15 \%$ and $16 \%$ after 6, 9 and 12 days, respectively as resumed in Table 1 and Fig. 4 $(\alpha<0.05)$.

In Fig. 5, the FancyTiles schema was reported in order to provide in a glance the effect of the enzyme on the free APs (Troise, Ferracane, Palermo, \& Fogliano, 2014). The tiles were built by considering the normal distribution of the concentration of the APs after 12 days; differently from our previous published paper the range for each class was obtained without using a semi-quantitative logarithmic scale but directly the concentration of the APs. The spectrum-inverted chromatic scale from blue (lowest concentration) to red (high- 
A-Loadings plot (PC1 and PC2: $77.3 \%$ )

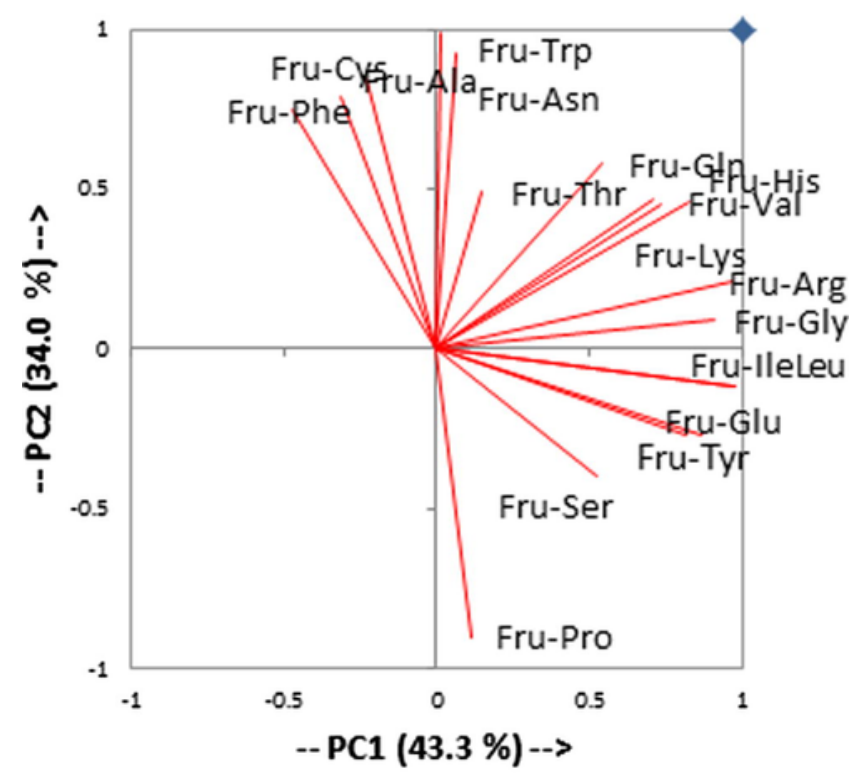

B-LLM and F LLM (PC1 and PC2: $77.3 \%$ )

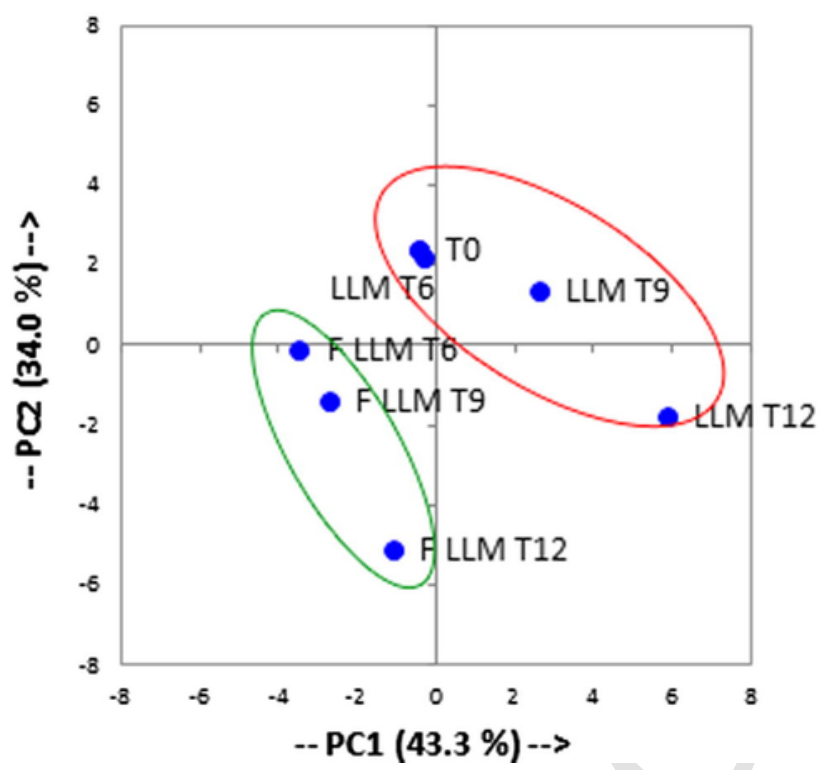

Fig. 2. Principal component analysis of Amadori products with and without the enzyme up to 12 days of incubation. (A) Variables plot and (B) samples plot on PC1 vs. PC2. PC1 and PC2 account for 43.3 and $34.0 \%$ of total variability within the samples. The letter "F" indicates LLM incubated along with the enzyme.

est value) was included in the minimum and maximum values after 12 days. The two APs having the highest concentration (Fru-Glu and Fru-Ala) were excluded in order to improve the differences among the other 16 APs. The FancyTiles schema highlighted the preferential activity of the enzyme towards Fru-Lys, red and orange tile in absence and in presence of the enzyme; towards Fru-Arg, and towards aliphatic APs, moving from dark green in presence of the enzyme, to light green in absence of the enzyme.

\section{Discussion}

In this paper the activity of Faox I in low lactose milk was evaluated towards two different classes of molecules: the protein bound MRPs and the free APs. We have previously demonstrated the effectiveness of Faox enzymes on the former class however the combination with the detection of the free APs has never been proposed. The concentration of furosine in absence of the enzyme was in line with the one reported by other authors for UHT milk (Claeys, Van Loey, \& Hendrickx, 2003; Fenaille et al., 2006; Henle, Zehetner, \& Klostermeyer, 1995). The data above confirmed the effectiveness of Faox I enzyme in limiting the bound MRPs already monitoring the classical MR marker furosine: its concentration in treated samples was much lower than the control samples and its formation is delayed. The similar concentration at 12 days depends on the two different kinetics since in the control sample at 12 days the furosine decrease is due to its conversion into more advanced glycation end products with development of color and off-flavor. The reactivity of fructose-lysine at $37^{\circ} \mathrm{C}$ can promote the $\alpha$-fragmentation or the $\beta$-cleavage of the sugar moiety with the consequent formation of dicarbonyls and other MRPs such as CML, CEL or the formation of cross link products such as pyrraline, pentosidine, crossline (Mossine \& Mawhinney, 2010).

Besides furosine, CML and total protein-bound lysine were both influenced by the presence of Faox I. In fact, a constant lower level of CML was detected during time in treated compared to untreated samples. As for furosine, the trend in presence and in absence of the enzyme revealed an increase of CML during the first 9 days while it remained almost constant at the end of the incubation. Beside the formation of CML from the Wolff pathway of oxidative glycosylation, the Namiki pathway, involving cleavage of the Schiff base and the Hodge pathway, proceeding by oxidative cleavage of the Amadori compound, it is worthy to highlight also the effects due to dicarbonyls, mainly glyoxal and the activity of 2,4-dioxo compounds (Kasper \& Schieberle, 2005). In this respect, the presence of the enzyme and its control of the formation of the fructose-lysine, promoted the reduction of CML. The concentration of CML was in agreement with the concentration reported in other quoted papers (Delatour et al., 2009; Hull, Woodside, Ames, \& Cuskelly, 2012; Tessier \& BirlouezAragon, 2012).

Regarding total lysine, treated samples showed similar levels during time compared to untreated samples where a slow reduction was observed up to 12 days incubation, indicative of a progress of glycation on the $\varepsilon$-amino group of protein-bound lysine during storage at $37^{\circ} \mathrm{C}$. An higher total lysine concentration indirectly confirmed the activity of the enzyme revealing that also other MRPs can be influenced by the deglycating activity. The concentration of total lysine was of the same order of magnitude as reported in other papers published by our group (Troise, Fiore, et al., 2014; Troise, Fiore, Wiltafsky, et al., 2015).

Data about protein-bound MRPs clearly showed an overall reduction of furosine and CML always higher than $10 \%$ revealing that Faox is an effective tool not only towards the deglycation of small peptides and amino acids, but also towards proteins. Despite the mechanism of action of Faox suggested that small substrates are required to fit the active site of the enzyme (Wu \& Monnier, 2003), we observed that the addition of the enzyme before the carbonyl attachments promoted the reduction of bound MRPs, thus promoting the decrease of overall glycation in LLM, since the first days of the incubation. This might be explained with local unfolding of the proteins at the moment they 

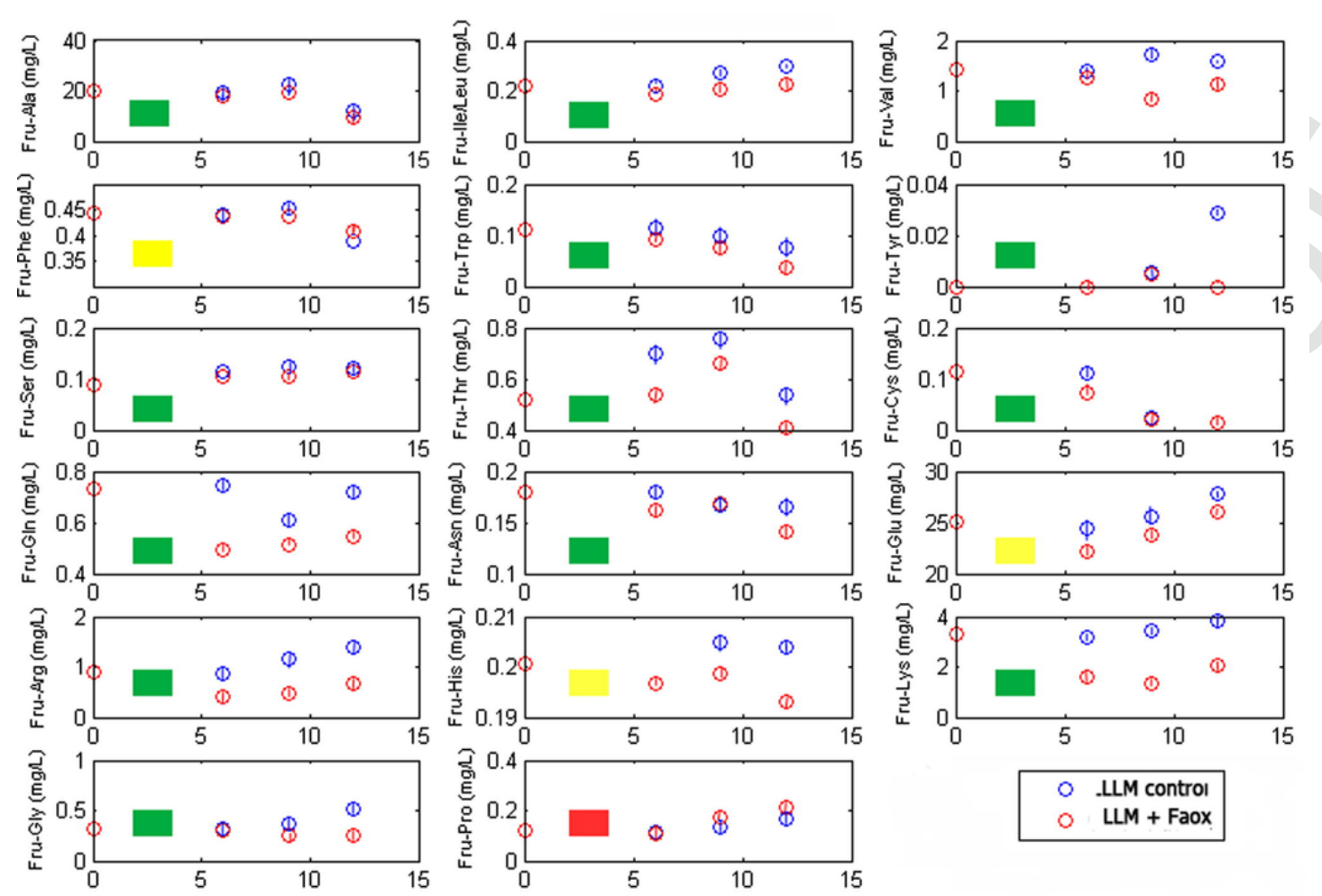

Fvolution of Amadori compounds in low lactose milk in presence and in absence of the enzyme after 0, 6, 9, 12 days of incubation. Blue dots: samples without Faox; red dots:

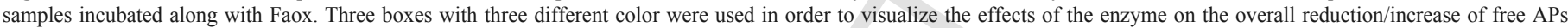

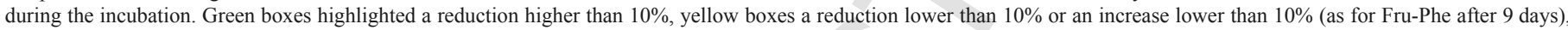

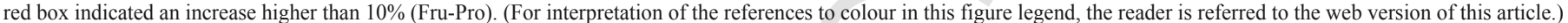

Table 1

Reduction of free Amadori products in low lactose milk in presence of Faox.

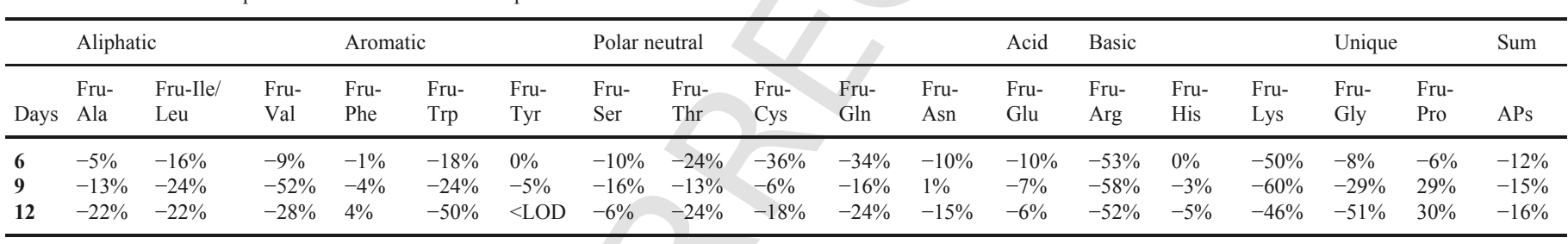

are glycated and in this way the neo-formed AP can be hydrolyzed by the enzyme.

It is worth noticing that $N \varepsilon$-(1-deoxy-D-tagatosyl)-lysine that represents the Amadori compound of galactose and lysine (Krause, Knoll, \& Henle, 2003) also contributes to the formation of CML and furosine through rearrangements and fragmentations similar to those of $N \varepsilon$-(1-deoxy-D-fructosyl)-lysine. In particular Ruttkat and Erbersdobler (1995) demonstrated that CML can be formed from lysine/fructose, lysine/sorbose, lysine/glucose and lysine/galactose model systems and this last resulted in the highest CML content. It is noteworthy that the effects of Faox on tagatose-amino acids need further investigations since in a model system the activity of the enzyme toward $N \varepsilon$-(1-deoxy-D-tagatosyl)-glycine was close to zero (Horiuchi \& Kurokawa, 1991).

Beside the standard protein-bound markers of the MR, the key aspects of this paper was the quantification of free APs that led to a detailed overview of Faox I effectiveness. For the first time, the Faox activity was evaluated towards the reduction of free APs, the ideal substrate for the enzyme in a complex system, such as LLM. A high res- olution mass spectrometry (HRMS) method combined with ion pairing liquid chromatography for the separation and quantification of free APs was used. This method allowed an accurate assessment of the thermal damage as well as of the storage by considering the modification in glycation of free amino acids (Troise, Fiore, Roviello, et al., 2015)

The principal component analysis (PCA) of the Amadori products as highlighted in Fig. 2A and B showed that the samples in presence of Faox I were characterized by negative values of the score plot (PC1 and PC2 were both negative) highlighting a positive effect in the deglycation of free APs, thus in an higher concentration of APs in absence of the enzyme. Interestingly, these results were partly in line with the ones previously reported for the substrate specificity of the enzyme in model systems, where the highest activity for Faox I was for lysine and glutamic acid (Collard et al., 2008).

Table 1 offers an outline of the effects of the enzyme in relationship to the concentration of APs. The catalytic activity of the enzyme was particularly evident towards basic APs, such as Fru-Arg and Fru-Lys where the guanidino side chain of arginine and the $\varepsilon$ - 


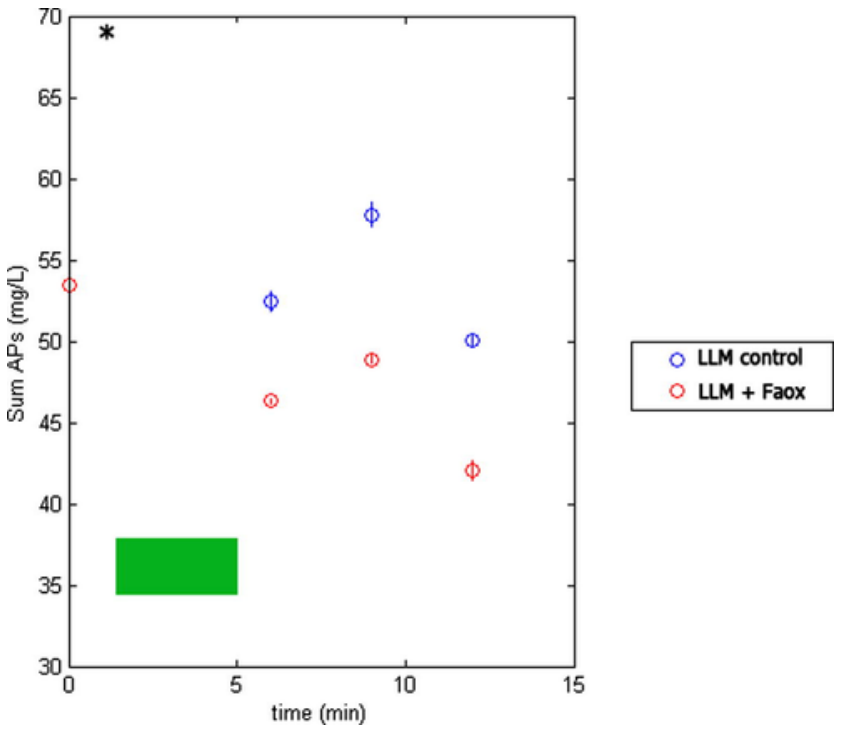

Fig. 4. Evolution of the total Amadori compounds in low lactose milk in presence and in absence of the enzyme after $0,6,9,12$ days of incubation. Blue dots: samples without Faox; red dots: samples incubated along with Faox. The green box highlighted a reduction higher than $10 \%$. The Tukey test was performed by comparing each time in presence and in absence of the enzyme ( $* \alpha<0.05$ after 6,9 and 12 days). (For interpretation of the references to colour in this figure legend, the reader is referred to the web version of this article.)

amino group of lysine primarily react with reducing sugars (Capuano et al., 2007; Collard et al., 2008). Reliable performances were also monitored for aliphatic APs and glycine where the small dimension of the molecules and the low steric hindrance promoted the optimal catalytic activity of the enzyme. From our study, it was evident that in the presence of Faox I some APs underwent deglycation with a slower rate compared to other APs. For instance, the aromatic APs Fru-Trp and the unique amino acid Fru-Gly reached 50\% deglycation compared to the corresponding untreated samples. The basic Fru-Arg and Fru-Lys were immediately affected by Faox I activity and their glycation lowered to around $50 \%$ already after the first 6 days of incubation. A minor activity was shown towards aliphatic APs Fru-Ala, Fru-Ile and Fru-Leu and Fru-Val which decreased their glycation after 12 days down to $22-28 \%$. A similar behavior was registered for neutral APs, Fru-Thr and Fru-Gln. Fru-Glu was deglycated in a lower percentage during storage, reaching $6 \%$ after 12 days.
These data represent the first example of the Faox activity evaluation towards free markers of the MR in a complex mixture such as milk and the concentrations reported for the above mentioned APsup to 12 days of incubation in presence of the enzyme clearly demonstrate its activity. In Fig. 4, the activity of the enzyme towards the sum of APs is reported, summarizing a significative reduction $(\alpha<0.05)$ in presence of the enzyme; moreover, the green box highlighted an overall reduction higher than $10 \%$ after 6,9 and 12 days. Despite the activity of the enzyme was evident for almost all the free APs, it is important to consider the different contribution of each compound in the definition of the total reduction, since the observed overall reduction is affected by the concentration of each single Amadori compound.

In Fig. 5, a snapshot of the Faox I activity towards free APs is reported. As highlighted, the FancyTiles approach contributed to the graphical representation of the control of APs formation along with the use of HRMS (Troise et al., 2014; Troise, Fiore, Roviello, et al., 2015). In this frame, the use of targeted approach efficiently depicted the activity of Faox I during the early stage of the MR.

\section{Conclusions}

Faox enzymes were investigated in our group as potential biotechnological tools to limit the MR in model systems (Capuano et al., 2007; Mennella et al., 2005) and in low lactose UHT milk (Troise, Fiore, et al., 2014). Results were very encouraging, since both enzymes, Faox I and II limited the amount of CML and b-HMF after 17 days of incubation at $37{ }^{\circ} \mathrm{C}$. In this paper a detailed study on the role of Faox I in limiting the detrimental effects of MR during a time course analysis up to 12 days at $37{ }^{\circ} \mathrm{C}$ was presented. Faox I revealed to be an helpful tool for the control of MR allowing us to depict new strategies in the control of the APs formation both on free precursors and proteins via furosine detection. Moreover, the activity of the enzyme was evaluated for the formation of protein bound CML showing that the formation of advanced stage of the MR can be controlled by the reduction of its early stage of MR.

For the first time, the activity of Faox was evaluated in a complex system by monitoring free and bound MRPs, revealing a clear relationship between free and bound markers. These results paved the way for the introduction of new strategies where the control of APs formation leads not only to the reduction of carbonyls loading, but also to the promotion of foods with better aroma and flavor. Further investigations will be carried out in conventional milk in order to eval-
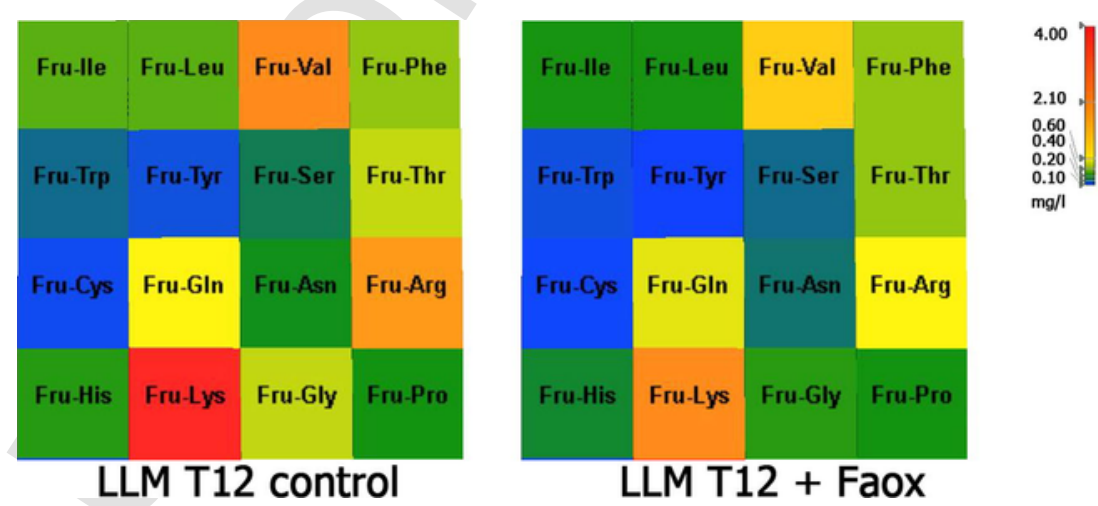

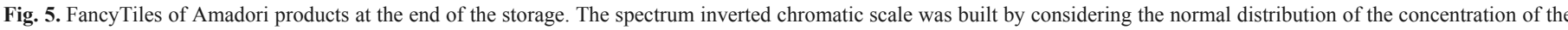

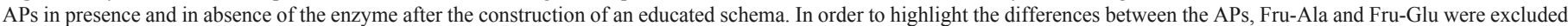
due to their higher concentration compared to other APs. The range was built by considering the minimum and maximum values. 
uate the effects of Faox I on the formation of disaccharide lactoseMRPs.

\section{Conflict of interest}

The Authors declare no conflict of interest.

\section{Acknowledgments}

Faox I cDNA was received as a kind gift from Prof. Monnier. We thank projects PON 02003953082360 and PON $02 \_00395 \_3082360$ for financial support to MB.

\section{References}

Bedinghaus, A.J., Ockerman, H.W., 1995. Antioxidative Maillard reaction-products from reducing sugars and free amino-acids in cooked ground pork patties. Journal of Food Science 60 (5), 992-995.

Capuano, E., Fedele, F., Mennella, C., Visciano, M., Napolitano, A., Lanzuise, S., ... Fogliano, V., 2007. Studies on the effect of amadoriase from Aspergillus fumigatus on peptide and protein glycation in vitro. Journal of Agricultural and Food Chemistry 55 (10), 4189-4195.

Claeys, W.L., Van Loey, A.M., Hendrickx, M.E., 2003. Kinetics of hydroxymethylfurfural, lactulose and furosine formation in milk with different fat content. Journal of Dairy Research 70 (1), 85-90.

Collard, F., Zhang, J., Nemet, I., Qanungo, K.R., Monnier, V.M., Yee, V.C., 2008. Crystal structure of the deglycating enzyme fructosamine oxidase (amadoriase II). Journal of Biological Chemistry 283 (40), 27007-27016.

Delatour, T., Hegele, J., Parisod, V., Richoz, J., Maurer, S., Steven, M., Buetler, T., 2009. Analysis of advanced glycation endproducts in dairy products by isotope dilution liquid chromatography-electrospray tandem mass spectrometry. The particular case of carboxymethyllysine. Journal of Chromatography A 1216 (12), 2371-2381

Delgado-Andrade, C., Seiquer, I., Navarro, M.P., Morales, F.J., 2007. Maillard reaction indicators in diets usually consumed by adolescent population. Molecular $\mathrm{Nu}-$ trition \& Food Research 51 (3), 341-351.

Fenaille, F., Parisod, V., Visani, P., Populaire, S., Tabet, J.C., Guy, P.A., 2006. Modifications of milk constituents during processing: A preliminary benchmarking study. International Dairy Journal 16 (7), 728-739

Fiore, A., Troise, A.D., Mogol, B.A., Roullier, V., Gourdon, A., Jian, S.E., ... Fogliano, V., 2012. Controlling the Maillard reaction by reactant encapsulation: Sodium chloride in cookies. Journal of Agricultural and Food Chemistry 60 (43), 10808-10814.

Friedman, M., 1996. Food browning and its prevention: An overview. Journal of Agricultural and Food Chemistry 44 (3), 631-653

Hellwig, M., Henle, T., 2014. Baking, ageing, diabetes: A short history of the Maillard reaction. Angewandte Chemie, International Edition in English 53 (39), 10316-10329.

Henle, T., 2005. Protein-bound advanced glycation endproducts (AGEs) as bioactive amino acid derivatives in foods. Amino Acids 29 (4), 313-322

Henle, T., Zehetner, G., Klostermeyer, H., 1995. Fast and sensitive determination of furosine. Zeitschrift Fur Lebensmittel-Untersuchung Und-Forschung 200 (3), 235-237.

Horiuchi, T., Kurokawa, T., 1991. Purification and properties of fructosylamine oxidase from Aspergillus Sp 1005. Agricultural and Biological Chemistry 55 (2), 333-338.

Hull, G.L.J., Woodside, J.V., Ames, J.M., Cuskelly, G.J., 2012. N-epsilon-(carboxymethyl)lysine content of foods commonly consumed in a Western style diet. Food Chemistry 131 (1), 170-174.

Jansson, T., Clausen, M.R., Sundekilde, U.K., Eggers, N., Nyegaard, S., Larsen, L.B., ... Bertram, H.C., 2014. Lactose-hydrolyzed milk is more prone to chemical changes during storage than conventional Ultra-High-Temperature (UHT) milk. Journal of Agricultural and Food Chemistry 62 (31), 7886-7896.

Kasper, M., Schieberle, P., 2005. Labeling studies on the formation pathway of $\mathrm{N} \varepsilon$-carboxymethyllysine in Maillard-type reactions. Annals of the New York Academy of Sciences 1043 (1), 59-62.
Krause, R., Knoll, K., Henle, T., 2003. Studies on the formation of furosine and pyridosine during acid hydrolysis of different Amadori products of lysine. European Food Research and Technology 216 (4), 277-283.

Mennella, C., Borrelli, R.C., Vinale, F., Ruocco, M., Fogliano, V., 2005. Substrate specificity of amadoriase I from Aspergillus fumigatus. Maillard Reaction: Chemistry at the Interface of Nutrition, Aging, and Disease 1043, 837-844.

Mossine, V.V., Mawhinney, T.P., 2010. 1-Amino-1-deoxy-D-fructose ("fructosamine") and its derivatives. Advances in carbohydrate chemistry and biochemistry $64,291-402$.

Nursten, H.E., 2005. The maillard reaction: Chemistry, biochemistry, and implications. Royal Society of Chemistry, Cambridge.

Pischetsrieder, M., Henle, T., 2012. Glycation products in infant formulas: Chemical, analytical and physiological aspects. Amino Acids 42 (4), 1111-1118.

Pripp, A.H., 2013. Statistics in food science and nutrition. Springer, Berlin-Heidelberg.

Ruttkat, A., Erbersdobler, H.F., 1995. N-epsilon-carboxymethyllysine is formed during heating of lysine with ketoses. Journal of the Science of Food and Agriculture 68 (2), 261-263

Somoza, V., 2005. Five years of research on health risks and benefits of Maillard reaction products: An update. Molecular Nutrition \& Food Research 49 (7), 663-672.

Takahashi, M., Pischetsrieder, M., Monnier, V.M., 1997. Isolation, purification, and characterization of amadoriase isoenzymes (fructosyl amine-oxygen oxidoreductase EC 1.5.3) from Aspergillus sp. Journal of Biological Chemistry 272 (6), 3437-3443.

Takahashi, M., Pischetsrieder, M., Monnier, V.M., 1997. Molecular cloning and expression of amadoriase isoenzyme (fructosyl amine: oxygen oxidoreductase, EC 1.5.3) from Aspergillus fumigatus. Journal of Biological Chemistry 272 (19), $12505-12507$.

Tessier, F.J., Birlouez-Aragon, I., 2012. Health effects of dietary Maillard reaction products: The results of ICARE and other studies. Amino Acids 42 (4), 1119-1131.

Troise, A.D., Fiore, A., Colantuono, A., Kokkinidou, S., Peterson, D.G., Fogliano, V., 2014. Effect of olive mill wastewater phenol compounds on reactive carbonyl species and Maillard reaction end-products in ultrahigh-temperature-treated milk. Journal of Agricultural and Food Chemistry 62 (41), 10092-10100.

Troise, A.D., Dathan, N.A., Fiore, A., Roviello, G., Di Fiore, A., Caira, S., ... Monti, S.M., 2014. Faox enzymes inhibited Maillard reaction development during storage both in protein glucose model system and low lactose UHT milk. Amino Acids 46 (2), 279-288.

Troise, A.D., Ferracane, R., Palermo, M., Fogliano, V., 2014. Targeted metabolite profile of food bioactive compounds by Orbitrap high resolution mass spectrometry: The "FancyTiles" approach. Food Research International 63 (Part B), 139-146.

Troise, A.D., Fiore, A., Roviello, G., Monti, S.M., Fogliano, V., 2015. Simultaneous quantification of amino acids and Amadori products in foods through ion-pairing liquid chromatography-high-resolution mass spectrometry. Amino Acids 47 (1), 111-124.

Troise, A.D., Fiore, A., Wiltafsky, M., Fogliano, V., 2015. Quantification of $N$ epsilon(2-furoylmethyl)-L-lysine (furosine), $N$ epsilon-(carboxymethyl)-L-lysine (CML), $N$ epsilon-(carboxyethyl)-L-lysine (CEL) and total lysine through stable isotope dilution assay and tandem mass spectrometry. Food Chemistry 188, , 357-364.

Troise, A.D., Fogliano, V., 2013. Reactants encapsulation and Maillard reaction. Trends in Food Science \& Technology 33 (1), 63-74.

Van Boekel, M., 1998. Effect of heating on Maillard reactions in milk. Food Chemistry 62 (4), 403-414.

Van Boekel, M., Fogliano, V., Pellegrini, N., Stanton, C., Scholz, G., Lalljie, S., ... Eisenbrand, G., 2010. A review on the beneficial aspects of food processing. Molecular Nutrition \& Food Research 54 (9), 1215-1247.

Wu, X., Monnier, V.M., 2003. Enzymatic deglycation of proteins. Archives of biochemistry and biophysics 419 (1), 16-24.

Wu, X., Takahashi, M., Chen, S.G., Monnier, V.M., 2000. Cloning of amadoriase I isoenzyme from Aspergillus sp.: Evidence of FAD covalently linked to Cys 342. Biochemistry 39 (6), 1515-1521.

Yaylayan, V.A., Huyghuesdespointes, A., 1994. Chemistry of Amadori rearrangement products - analysis, synthesis, kinetics, reactions, and spectroscopic properties. Critical Reviews in Food Science and Nutrition 34 (4), 321-369. 